\title{
LIMITES CONSTITUCIONAIS À REGULAMENTAÇÃO DO DIREITO FUNDAMENTAL À LIBERDADE DE REUNIÃO PELO LEGISLADOR ORDINÁRIO
}

\author{
Andrea Neiva Coelho de Medeiros ${ }^{1}$
}

\section{Resumo:}

O presente trabalho tem por escopo o estudo dos limites constitucionais impostos ao legislador ordinário em face da possibilidade de regulamentação do direito a liberdade de reunião. De inicio, será abordado o direito a liberdade de forma genérica, tecendo comentários necessários ao desenvolvimento do tema central. Em seguida, o estudo focara nos aspectos históricos e jurídicos do direito a liberdade de reunião. Apos isso, delimitar-se-á a área de proteção do direito a reunião. Por fim, analisar-se-á quais os limites impostos ao legislador infraconstitucional para a regulamentação do direito de reunião e a consequente permissão de intervenções estatais.

Palavras-chave: direito fundamental a liberdade de reunião; direito de reunião; direito a liberdade de reunião; direito a liberdade; limites ao legislador infraconstitucional.

\section{CONSTITUTIONAL LIMITS TO THE REGULATION OF THE FREEDOM OF ASSEMBLY BY THE REGULATORY LEGISLATOR}

\begin{abstract}
:
The purpose of this study is to analyze the limits imposed to the legislator in the regulation of the freedom of assembly. Initially, the rights to be free will be approached in a generic way, providing the necessary comments for the development of the theme. Then, the work will focus on the historical and legal aspects of the freedom of assembly. After, the area of protection of the freedom of assembly will be delimited. Finally, it will be analyzed the limits imposed to the ordinary legislator for the regulation of the freedom of assembly and the permission of state interventions.
\end{abstract}

Keywords: fundamental right to freedom of assembly; freedom of assembly; right to freedom of assembly; right to be free; limits to the infra-constitutional legislator.

\section{Introdução}

$\mathrm{O}$ direito à liberdade norteia a sociedade moderna e assegura aos seus cidadãos garantias mínimas de não interferência estatal em sua vida privada ou por suas ações cotidianas básicas. De fato, esse ideário burguês - bandeira maior levantada principalmente nas revoluções francesa e americana - impõe ao Poder Público limitações de seus poderes e protegem o cidadão contra abusos advindos do Estado.

\footnotetext{
${ }^{1}$ Advogada, graduada em Direito pela Universidade Federal da Paraíba; Especialista em Direito Material e Processual do Trabalho pela Escola Superior da Magistratura da 13a Região; Mestranda na Universidade Federal do Rio Grande do Norte na área de concentração Constituição e Garantias de Direito.
} 
A liberdade genérica mereceu proteção constitucional e está disposta no inciso segundo do art. $5^{\circ}$ da Constituição Federal brasileira. Outros incisos do mesmo artigo foram dedicados a pormenorizar algumas liberdades, tais quais, de manifestação, associação, de crença, entre outras tão importantes quanto. Uma dessas liberdades específicas será alvo de discussão neste estudo: o direito à liberdade de reunião - positivado no art. $5^{\circ}$, XVI da CF.

Escândalos de corrupção, má gestão do dinheiro público e a recessão econômica resultaram em uma crise política e instabilidade social no Brasil. Diante desse panorama, a população começa a se insurgir contra os seus representantes para lutar por seus direitos e a reunião popular é um meio eficaz e bastante utilizado para pressionar os governantes a agirem conforme a vontade do povo.

De fato, nos últimos anos, houve um aumento da frequência e tamanho das manifestações políticas, a dizer: por passe livre; em defesa ou contra o impeachment; oposição às reformas previdenciárias e trabalhistas; entre outras. Nesse cenário, a discussão sobre o direito à liberdade de reunião ganha maior relevo, tendo em vista a necessidade de assegurar o seu exercício e de admitir a atuação estatal em caso de abuso desse direito.

A ausência de norma infraconstitucional regulamentadora da matéria não significa que o direito de reunião possa ser exercido de forma absoluta. Assim como acontece em todos os outros direitos fundamentais, o direito de reunir-se livremente não é ilimitado. O próprio constituinte já recortou a área de proteção e impôs determinadas condições ao seu exercício no mesmo dispositivo que o assegura. Contudo, isso não deve inibir a atuação do legislador infraconstitucional em tratar do tema, uma vez que apenas deixa contornos claros a serem respeitados, sob pena de inconstitucionalidade.

Ocorre que o legislador infraconstitucional, ao tentar regulamentar o direito fundamental à liberdade de reunião, não deve se preocupar apenas com os limites dispostos no art. $5^{\circ}$, XVI da CF. A defesa dos demais direitos fundamentais e de outros bens jurídicos protegidos pela Constituição Federal devem orientar tais proposições legislativas.

Alerte-se que, neste trabalho, o direito à liberdade de reunião será abordado sob o enfoque da sua natureza jurídica de direito fundamental - positivado no ordenamento jurídico brasileiro. Contudo, isto não impede uma visitação às origens deste direito no sistema jurídico 
internacional, uma vez que o seu enfoque enquanto direitos humanos servirá ao entendimento dos valores e finalidades buscada com a sua proteção. ${ }^{2}$

Da mesma forma, não se pretende incluir no desenvolvimento deste estudo o exercício do Poder Constituinte Reformador ${ }^{3}$, quer-se, assim, manter o foco na regulamentação desse direito, evitando falar sobre a sua possível alteração ou supressão. Saliente-se que tal discussão imporia uma análise detalhada das cláusulas pétreas e sua hermenêutica, assuntos dignos de uma pesquisa científica específica e de um exame pautado em outros princípios não aludidos aqui.

Enfim, realizou-se esse corte metodológico com o escopo de delimitar o objeto ao possível tratamento que o legislador ordinário poderá dispensar (ou não) à regulamentação do direito fundamental à liberdade de reunião, almejando assegurar o exercício desse direito e sua harmonia com as demais liberdades fundamentais e outros bens jurídicos tutelados pela Constituição.

\section{Direito geral à liberdade}

Liberdade é um termo amplo e transmite a ideia de ausência de restrições, de permissão quase total. Em certos momentos esse termo é, inclusive, romantizado e carrega uma imagem de algo benéfico e perfeito. Robert Alexy (2008, p. 218) denomina essa impressão linguística da palavra liberdade de "conotação emotiva" e assevera ser, a utilização da característica "livre", encharcada de valoração positiva. Nas palavras de Aldous Huxley (apud ALEXY, p. 218): "Liberdade é um nome maravilhoso. É por isso que você está tão ansioso para fazer uso dele. Você acha que, se você chamar o encarceramento de verdadeira liberdade, as pessoas ficarão atraídas pela prisão. E o pior de tudo é que você tem razão".

No entanto, não é esta a liberdade tratada pela constituição, e sim a liberdade jurídica, limitada por vários aspectos, inclusive, pela liberdade de uma terceira pessoa. De fato, a liberdade total concedida a um indivíduo pressupõe a limitação à liberdade de outro

\footnotetext{
${ }^{2}$ Não cumpre aqui dissertar sobre as diferenças conceituais entre direitos humanos e direitos fundamentais, mas, em linhas gerais: diz-se humanos aqueles direitos do homem inseridos na ordem internacional, já direitos fundamentais são aqueles de mesma natureza só que constantes em determinada ordem jurídica interna de um Estado. Isso, contudo, não significa que são categorias totalmente separadas de direitos dos homens. Ao contrário, em diversos momentos há um verdadeiro intercâmbio de proteções, aumentando-se a cada dia o âmbito de intercessão entre esses dois "grupos". Ver mais em: CUNHA JR, 2008, p. 520.

${ }^{3}$ A escolha da expressão "Poder Constituinte Reformador" é meramente didática, não se pretendendo com ela retratar a natureza jurídica do Poder Reformador e muito menos adentrar em uma discussão sobre os seus limites. Esta autora, inclusive, partilha da ideia que o Poder Reformador é mais um Poder Constituído que Constituinte, ou, na expressão de Bonavides (2004, p. 149): "Poder Constituinte Constituído".
} 
indivíduo, bem como, a liberdade de dois indivíduos é impossível sem que haja restrição a ambas. Tal pensamento é corporificado pelo dito popular: "Minha liberdade termina onde começa a do outro".

$\mathrm{O}$ ordenamento constitucional brasileiro concede proteção ao direito geral à liberdade e também a formas específicas de exteriorização dessa liberdade, tais quais, o direito à livre manifestação, ao exercício profissional sem embaraços, à autonomia privada, e outras inúmeras liberdades elencadas no decorrer do art. $5^{\circ}$ da Constituição brasileira.

Nesse contexto, Leonardo Martins (2012, p. 50) identifica o caráter subsidiário da liberdade geral de ação em relação às expressões particulares deste direito, assim, evita-se a existência de lacunas na proteção constitucional à liberdade. Ao contrário, favorece a concorrência de direitos fundamentais, podendo a cumulação ser ideal ou aparente. No primeiro caso, há uma multiplicidade de parâmetros para defesa do direito, já na segunda situação, a subsunção da conduta a um parâmetro exclui a utilização de outros. (DIMOULIS; MARTINS, p. 172)

Com base nesse raciocínio, havendo a violação a alguma liberdade específica, em caso de afastamento deste parâmetro, poderá ser utilizada a proteção genérica inserida no art. $5^{\circ}$, caput da CF. Contudo, essa subsidiariedade é limitada pela interpretação sistêmica do dispositivo utilizado como parâmetro, por exemplo, uma reunião com armas não ganhará guarida sob o direito genérico à liberdade, haja vista a garantia desse direito expressamente excluir da sua área de proteção tal forma de reunir-se. (DIMOULIS; MARTINS, p. 172)

Acrescente-se, também, que a doutrina ${ }^{4}$ é firme ao encarar o direito à liberdade ${ }^{5}$ de não agir como condição de existência da própria liberdade de agir. Robert Alexy (2008, p. 222), aliás, define a liberdade jurídica como uma associação entre a permissão jurídica de fazer e a permissão jurídica de não-fazer e a designa como faculdade. Na mesma linha, Konrad Hesse (2009, p. 70) corrobora sempre estarem presentes concomitantemente essa dupla liberdade (de ação ou de omissão). Não poderia ser de outra forma, uma vez que, ao não admitir a possibilidade de escolha, haveria a mera obrigação de agir conforme uma conduta assim, o ato deixaria de ser um direito e passaria a ser um dever.

\footnotetext{
${ }^{4}$ Nesse sentido: ALEXY, 2008; HESSE, MENDES, CANOTILHO.

${ }^{5}$ Por esta expressão aqui posta, entenda-se toda e qualquer espécie de liberdade protegida constitucionalmente seja geral ou específica, a exemplo dos direitos à liberdade de reunião, de manifestação, de crença, de manifestação, entre outros.
} 
Canotilho (1993, p. 539), por sua vez, identifica a "alternativa de comportamento" como fundamental à caracterização de uma liberdade, posto que essa componente negativa constitui uma dimensão essencial. Diante dessas ideias, entende-se que, na ausência da opção não-fazer/não-ser/não-ter, não haverá liberdade, mas sim uma obrigação de fazer/ser/ter e essa obrigatoriedade é incompatível com a caracterização da liberdade.

Além dessa necessária coexistência entre o direito de agir e não agir, o direito geral à liberdade caminha ao lado do princípio da legalidade e é por ele limitado. Sob a perspectiva de Hobbes (2003, p. 187): "Nos casos em que o soberano não tenha estabelecido uma regra, o súdito tem a liberdade de fazer ou de omitir, conformemente a sua discrição". Contudo, essa legalidade também está adstrita aos ditames constitucionais e à proteção de bens jurídicos fundamentais. Assim, diz-se que a liberdade e a legalidade se autolimitam a fim de prevalecer a ordem e a paz social. Essa contenção recíproca abrange não apenas o direito geral à liberdade como também as liberdades específicas pormenorizadas ao longo do artigo quinto da Constituição.

Konrad Hesse (2009, p. 77) condiciona a existência da liberdade individual à liberdade social. Deveras, para possibilitar cidadãos livres é essencial que a sociedade também o seja e o inverso também é verdadeiro, afinal, não se pode construir uma sociedade livre com seus homens coagidos. Destarte, esses cidadãos devem ter a capacidade e a vontade de autodeterminar-se e colaborar através de discussões livres e públicas sobre a construção do Estado em que vive.

Hesse (2009, p.77) conclui, ainda, que um Estado de Direito deve buscar amparo à sua ordem democrática nos direitos fundamentais, em especial àqueles de caráter político como os de manifestação, associação, reunião e liberdade religiosa. Esses direitos têm por finalidade assegurar a livre e igualitária participação dos cidadãos na conformação da vontade política estatal. Outrossim, tais direitos proporcionam oportunidades para que as minorias políticas sejam ouvidas e consigam influenciar na formação da opinião pública.

De fato, o direito de reunião, objeto dessa pesquisa e incluso no rol acima posto, tem por base o valor democrático e a busca por permitir a participação efetiva do cidadão na constituição da vontade política de uma sociedade, bem como, conceder o poder de lutar por suas ideologias e publicizar tais disputas ideológicas. Passa-se ao seu estudo detalhado.

\section{Direito fundamental à liberdade de reunião}

Revista Brasileira de Direitos e Garantias Fundamentais | e-ISSN: 2526-0111 | Brasília | v. 3 | n. 1 | p. 99 - 117 | Jan/Jun. 2017. 
A princípio, todas as observações realizadas no item anterior sobre o direito geral à liberdade aplicam-se também ao direito à liberdade de reunião que está positivado no art. $5^{\circ}$, XVI da Constituição Federal brasileira, assegurando a todos o poder de "reunir-se pacificamente, sem armas, em locais abertos ao público, independentemente de autorização, desde que não frustrem outra reunião anteriormente convocada para o mesmo local, sendo apenas exigido prévio aviso à autoridade competente".

Segundo Robert Alexy (2008, p. 499), os direitos fundamentais ligados ao exercício político (entre eles, o direito de reunião) abrem a possibilidade para participação na concretização da vontade legislativa e, concomitantemente, impõem restrições à competência do legislador. Desta forma, ao mesmo tempo que salvaguardam o processo democrático e acreditam na sua racionalidade, não confiam ilimitadamente nesse sistema, demonstrando, assim, uma "conexão intrínseca" ao lado de uma "relação de tensão" entre o princípio democrático e esses direitos fundamentais fomentadores da participação na vontade política do Estado.

Ao buscar as raízes históricas do surgimento do direito fundamental à liberdade de reunião, solidifica-se ainda mais a sua índole democrática e política. A Declaração da Pensilvânia (1776) é a mais antiga referência no direito positivo à liberdade de reunião, incluída no conteúdo do seu artigo 16, reconhecia que: “o povo tem o direito de reunir, de deliberar o bem comum, de dar instruções a seus representantes e de solicitar à legislatura, por meio de mensagens, de petições ou de representações, a emenda dos erros que considere por ela praticados".

Observa-se que o dispositivo em comento faz referência clara e direta a atos essenciais à formação da vontade política da sociedade e dos seus representantes. De fato, em um país democrático, a liberdade de reunião deverá ser a regra enquanto o tolhimento a esse direito, a exceção. Em outras palavras, tratando-se de um Estado Democrático de Direito, não se pode proibir seus cidadãos de se reunirem e deliberarem a respeito da situação política estatal.

A preocupação internacional com o respeito e amparo ao direito à liberdade de reunião não se restringe à Declaração da Pensilvânia (1776), outros documentos também dedicaram espaço à proclamação desse direito, tais quais, o Pacto Internacional sobre direitos 
civis e políticos (art. 21), o Pacto de San Jose da Costa Rica (art. 15) e até mesmo a Convenção sobre os direitos da criança e do adolescente (art. 15). ${ }^{6}$

Em que pese a importância do tratamento internacional dispensado ao direito de reunião, é o art. $5^{\circ}$, XVI que impõe os principais limites (alguns claros, outros de forma indireta como se verá adiante) ao poder discricionário concedido ao legislador infraconstitucional. Outrossim, os referidos tratados não trazem grandes divergências do modelo adotado pela Constituição Federal brasileira. Desta forma, a qualidade de direito fundamental será o guia deste estudo e os tratados apenas um apoio complementar à sua interpretação.

\section{4. Área de proteção constitucional do direito fundamental à liberdade de reunião}

Antes de abordar os limites impostos à regulamentação do direito de reunião pelo legislador infraconstitucional, cumpre delimitar a área de proteção abrangida pelo art. $5^{\circ}$, XVI da $\mathrm{CF}$, uma vez que só será caracterizada de fato a intervenção estatal quando recair dentro da área de proteção do direito (DIMOULIS; MARTINS, 2014, p. 149).

$\mathrm{O}$ art. $5^{\circ}$, XVI da CF prescreve que "todos podem reunir-se pacificamente, sem armas, em locais abertos ao público, independentemente de autorização, desde que não frustrem outra reunião anteriormente convocada para o mesmo local, sendo apenas exigido prévio aviso à autoridade competente".

\subsection{Caráter Subjetivo da área de proteção do direito fundamental à liberdade de reunião}

$\mathrm{O}$ verbo reunir-se semanticamente implica a necessidade de no mínimo duas pessoas para o exercício desse direito. Realmente, é impensável a realização de uma reunião de forma solitária, de uma pessoa consigo mesmo, haja vista que ofende a lógica apresentada com o verbo nuclear deste mandamento.

Com base nisso, a doutrina impõe como condição ao exercício do direito fundamental à liberdade de reunião a existência de uma pluralidade de pessoas. Luiz Fux (2013, p. 178-179) ressalta que, apesar desse requisito extraído da interpretação do

\footnotetext{
${ }^{6}$ Lembre-se que o conteúdo desses tratados - incluído neles o direito à reunião - possuem natureza jurídica de supralegalidade conforme decisão do Supremo Tribunal Federal no RE 466343 (Voto do Ministro Gilmar Mendes, Tribunal Pleno, julgamento em 3.12.2008, DJe de 5.6.2009). Contudo, tal afirmação não parece ter relevância jurídica uma vez que o direito de reunião já possui raízes constitucionais. Mesmo assim, a preocupação internacional relacionada ao tema demonstra o seu grau de importância para a ordem democrática mundial.
} 
dispositivo, não há exigência de um número mínimo de pessoas, devendo prevalecer o entendimento que a aglomeração de duas pessoas (respeitados os demais requisitos analisados a seguir) já é apta a configurar o exercício do direito de reunião.

Leonardo Martins e Dimitri Dimoulis (2014, p. 134) mencionam também que "uma reunião pode ser definida como encontro de pelo menos três pessoas, segundo entendimento orientado pelo uso linguístico geral do termo, ou até mesmo de duas pessoas, segundo entendimento lógico-literal". Adotando uma interpretação com base no princípio da máxima efetividade dos direitos fundamentais, parece mais razoável admitir como limite mínimo para a possível configuração do direito de reunião o encontro de duas pessoas (CANOTILHO, 2007, p. 637).

Gilmar Mendes (2000, p. 157) apresenta o direito fundamental à liberdade de reunião como exemplo de direito individual de expressão coletiva, ou seja, o indivíduo é titular do direito, mesmo que não possa ser isoladamente exercido por ele. Na mesma linha, Dimoulis e Martins (2014, p. 56) diferenciam os direitos coletivos - de titularidade individual, mas de expressão coletiva - dos direitos difusos que a coletividade atinge a própria titularidade do direito e não apenas o seu exercício.

$\mathrm{O}$ artigo $5^{\circ}$, XVI da CF determina que a liberdade de reunião é um direito de "todos". Ao utilizar uma expressão tão generalista, a titularidade desse direito cai na regra geral disposta no caput do artigo, qual seja, "brasileiros e estrangeiros residentes no Brasil" (DIMOULIS; MARTINS, 2014, p. 72).

Todavia, apesar de o termo empregado ser universalista, surgem alguns questionamentos lógicos sobre a titularidade do direito fundamental à liberdade de reunião: os presos podem reunir-se livremente? Por ser um direito eminentemente de caráter político, sua titularidade está adstrita aos cidadãos em pleno gozo dos direitos políticos?

No que tange ao primeiro questionamento, a prisão acarreta o cerceamento da liberdade e não a sua supressão, desta forma, a interpretação sistêmica leva ao entendimento que tal restrição à liberdade do preso (seja ele definitivo ou provisório) alcança também o direito de manifestação. De fato, não se concebe imaginar uma pessoa com sua liberdade cerceada exercendo livremente o direito de reunião. Contudo, isso não significa sua exclusão da titularidade desse direito, mas uma vedação ao seu exercício por outras razões também protegidas constitucionalmente. 
Já no que diz respeito à segunda indagação, embora o direito à liberdade de reunião tenha sua origem e seu caráter precipuamente políticos, tal natureza não é obrigatória, podendo a reunião assumir uma índole religiosa ou cultural. Assim, a resposta para a referida pergunta deve ser negativa. Outrossim, com base no princípio hermenêutico da máxima efetividade dos direitos fundamentais, entre duas interpretações possíveis, deve ser empregada aquela que de maior abrangência e potencialidade a esta categoria de direitos.

Ademais, ao utilizar uma interpretação sistêmica, afere-se que se os direitos políticos fossem condição para a titularidade ao direito de reunião, o art. 15 da Convenção sobre os direitos da criança $(1989)^{7}$ não teria razão de existir, uma vez que crianças e adolescentes até os 16 anos ainda não são considerados cidadãos em sentido jurídico do termo, ou seja, não possui o pressuposto para gozarem os direitos políticos. Da mesma maneira, não parece justo excluir do direito de reunião a parcela da sociedade que, apesar de não poder exercer o voto, permanece submetida às vontades políticas dos governantes e legisladores.

\subsection{Caráter Objetivo da área de proteção do direito fundamental à liberdade de reunião}

Do texto disposto no art. $5^{\circ}$, XVI da CF extrai-se diversas exclusões feitas pelo constituinte à proteção ao direito de reunião. Segue o estudo realizado de forma pormenorizada através da interpretação gramatical e linguística das expressões utilizadas no referido artigo.

\subsection{1. "reunião"}

O significado linguístico do verbo "reunir-se" carrega consigo ao menos três ideias principais: a da pluralidade de participantes (discussão tratada no item anterior); o local seja igual para todos que pretendem participar dessa reunião; e o propósito comum interligando esses integrantes.

Essa comunhão de propósitos é fundamental para diferenciar as reuniões protegidas pelo art. $5^{\circ}$, XVI da CF daquelas aglomerações de pessoas em determinado local

\footnotetext{
7 "Artigo 15: 1. Os Estados Partes reconhecem os direitos da criança à liberdade de associação e à liberdade de realizar reuniões pacificas. 2. Não serão impostas restrições ao exercício desses direitos, a não ser as estabelecidas em conformidade com a lei e que sejam necessárias numa sociedade democrática, no interesse da segurança nacional ou pública, da ordem pública, da proteção à saúde e à moral públicas ou da proteção aos direitos e liberdades dos demais."
} 
para um propósito particular de cada participante (DIMOULIS; MARTINS, 2014, p. 134135). Certamente a preocupação do constituinte ao estabelecer o direito fundamental à liberdade de reunião não foi proteger o agrupamento, por mais numeroso que seja, de pessoas para acompanhar um determinado espetáculo (artístico, esportivo, cultural).

Por exemplo, diversas manifestações ${ }^{8}$ políticas já ocorreram na Praia de Copacabana (Rio de Janeiro/RJ), onde inúmeras pessoas foram até lá por partilhar de um determinado sentimento comum. O mesmo local, no último dia de todos os anos, é palco de uma enorme festa de reveillon e cada pessoa ali comparece com a mesma intenção: comemorar a virada de ano.

Entretanto, é nítida a diferença da natureza desses dois eventos: no primeiro, o propósito é geral e as pessoas estão por ele interligadas, necessitando uma das outras para alcançar êxito na luta política; no segundo, o propósito é individual (mesmo que idênticos) e as pessoas não estão conectadas entre si, agem de maneira autônoma e independente, sem precisar (pelo menos, não juridicamente) de outras pessoas para alcançar o seu intento.

Decerto, o fato de milhares de pessoas estarem juntas em um estádio assistindo a uma partida de futebol não implica um propósito comum, apenas um propósito igual. Portanto, a comunhão do propósito é essencial para a inclusão da aglomeração de pessoas na área de proteção do direito fundamental à liberdade de reunião.

A identidade do local onde ocorrerá a reunião também é condição para que esteja sob a guarida constitucional. Ainda que haja um propósito comum, a explanação da sua intenção e a sua defesa individual em locais distintos não configuram uma reunião propriamente dita, independentemente da concomitância entre os fatos.

Além disso, há quem exclua da área de proteção as reuniões virtuais ocorridas com o auxílio ou por intermédio de novas tecnologias de informática, a exemplo de chats virtuais ou videoconferências. Assim, a presença física dos participantes no local seria essencial para o exercício do direito de reunião (FUX, 2013, p. 179; SCHIMDT; PIEROTH; SCHILINK, 2012, p. 183 apud DIMITRI; MARTINS, 2014, p. 134). Saliente-se que essa exclusão não significa a ausência de proteção a tais eventos, visto que poderão ser subsumidas ao amparo do direto fundamental à liberdade de expressão.

\footnotetext{
${ }^{8}$ Em que pese configurar o exercício do direito de reunião, o termo manifestação é comum e amplamente empregado pela mídia, sociedade e cidadãos como a concretização do direito de reunir-se. Contudo, não pode ser confundido com o seu homônimo de significado jurídico distinto: direito à livre manifestação.
} 
Destarte, a área de proteção do direito fundamental à liberdade de reunião inclui apenas aquelas que ocorram através de um encontro físico, em determinado local e em busca de um propósito comum.

\subsection{2. "pacificamente" e "sem armas"}

Em que pese ambas as expressões estarem interligadas, devem ser interpretadas de forma autônoma. Afinal, nem toda reunião sem armas é pacífica ${ }^{9}$, bem como, nem toda reunião pacífica ocorre sem armas ${ }^{10}$. Outrossim, em uma análise sintática do texto posto no art. $5^{\circ}$ da CF, verifica-se que o posicionamento da vírgula demonstra essa independência.

Ao abordar a abrangência da exigência constitucional ao caráter pacífico das reuniões, Luiz Fux (2013, p. 183) assevera que "por reuniões pacíficas, devem ser entendidas aquelas em que há um estado de tranquilidade ou de ausência de desordem e de perturbação à ordem pública". Fux defende, ainda, não poder ser considerada pacífica, qualquer reunião que coloque em risco a integridade física dos participantes ou de terceiros, bem como aquelas em que haja dilapidação patrimonial alheia.

Portanto, a utilização de violência (seja contra pessoas ou objetos) quebra a pacificidade e retira a legitimidade da reunião - que, por disposição constitucional, está excluída da área de proteção do direito fundamental em questão - podendo, assim, ser repelida através de intervenção estatal.

$\mathrm{O}$ art. $5^{\circ}$ da CF também exige que a reunião seja realizada "sem armas". Contudo, não fica claro se esse termo abrange as armas brancas ou, em seu sentido restritivo, apenas as armas de fogo. O porte de facas, espadas, serras pelos manifestantes oferece risco à incolumidade dos outros participantes e de terceiros alheios ao movimento político. Desta forma, Fux (2013, p. 184) entende que a expressão "sem armas" foi empregada em seu sentido amplo, devendo-se incluir, então, as armas brancas.

Contudo, o referido autor faz um alerta: o porte de arma não possui o condão de deslegitimar a reunião se configurar uma situação isolada. Por exemplo, caso seja identificado

\footnotetext{
${ }^{9}$ Por exemplo, uma reunião em que as pessoas se ataquem com o auxílio de outros utensílios que não sejam armas (pedras, galhos, fogo) ou até mesmo sem a utilização de qualquer instrumento (troca de socos, pontapés, cotoveladas).

${ }^{10}$ Por exemplo, a ocorrência de uma reunião contra o desarmamento civil em que as pessoas portem armas como símbolos de uma luta, sem qualquer pretensão de utilizá-las de fato.
} 
um manifestante armado (ou alguns, desde que não o seja de forma generalizada), a polícia deverá apreender sua arma ou então deverá expulsá-lo(s) do evento.

Desse modo, afere-se que o porte de armas, qualquer que seja a sua natureza, desconfigura o direito fundamental à liberdade de reunião e não está abarcado pela sua área de proteção.

\subsection{3. "locais abertos ao público"}

$\mathrm{O}$ art. $5^{\circ}$, XVI da CF refere-se unicamente a reuniões ocorridas em "locais abertos ao público". Isso não significa que as reuniões privadas estejam proibidas, ao contrário, elas possuem proteção de outros direitos fundamentais, como a inviolabilidade do domicílio.

Deste modo, por existir a delimitação expressa a reuniões ocorridas em locais abertos ao público, as reuniões desenroladas em ambiente privado estão fora da área de proteção do direito fundamental em debate, contudo, não estão fora da salvaguarda constitucional, uma vez que há outros dispositivos que podem garantir a sua regular ocorrência.

A expressão "aberto ao público" não diz respeito nem exclusiva, nem necessariamente a bens públicos. De fato, um ambiente particular pode ser intitulado com aberto ao público (p. ex., shoppings centers, supermercados), e, igualmente, um bem público pode ser de acesso restrito (p. ex., o Palácio da Alvorada, escolas).

Sendo assim, incontestavelmente os bens que sejam públicos e de livre acesso como praias, avenidas e praças - estão inclusos na área de proteção do direito à reunião. A discussão doutrinária deve recair sobre aquelas situações em que o ambiente escolhido para a realização da reunião não possui essa dupla característica (ou não pertence ao Estado ou não é aberto ao público).

Fica claro que, se o acesso de determinado ambiente está restrito a certas pessoas, reuniões que ali ocorram não estão protegidas constitucionalmente pelo art. $5^{\circ}$, XVI da CF. Então, o direito de reunião não poderá ser invocado por aqueles que pretendam realizá-la em locais como o gabinete de um juiz, a residência oficial de um Governador, a sala de um Ministro de Estado, entre outros de mesma característica.

Recentemente, no Brasil, aconteceram manifestações em que escolas e universidades públicas eram os locais escolhidos para sua ocorrência. O problema é que as escolas não possuem acesso irrestrito, haja vista que apenas pessoas que a ela estejam 
vinculados (alunos, professores, funcionários) podem adentrar em suas dependências e o mesmo raciocínio se aplica às salas universitárias. ${ }^{11}$ De fato, em tempos normais, não se admite a entrada indiscriminada de pessoas nos referidos ambientes, uma vez que ofereceria riscos à segurança dos alunos e à ordem condizente com o local.

Em que pese a enorme discussão sobre a legitimidade dessas "ocupações", é razoável entender que o direito de reunião não pode ser invocado para assegurar a sua ocorrência, considerando que, por não ocorrerem em "locais abertos ao público", estão excluídos da sua área de proteção. ${ }^{12}$

Pelo sentido literal da locução "locais abertos ao público", afere-se que os bens privados que tenham acesso aberto ao público devam ser incluídos como passíveis de realização de reunião, a exemplo de shoppings centers. Contudo, é evidente o choque entre o princípio da autonomia privada, direito de propriedade e o direito fundamental à liberdade de reunião. Nesse caso, enquanto o legislador infraconstitucional não se habilita a resolver esse conflito, cumpre uma interpretação casuística sobre qual direito em questão prevalecerá no caso concreto apresentado.

4.2.4. "independentemente de autorização (...) sendo apenas exigido prévio aviso à autoridade competente".

$\mathrm{O}$ art. $5^{\circ}$, XVI da CF afirma que o direito de reunião poderá ser exercido "independentemente de autorização, desde que não frustrem outra reunião anteriormente convocada para o mesmo local, sendo apenas exigido prévio aviso à autoridade competente".

Ao utilizar a expressão "independente de autorização", o constituinte brasileiro excluiu do Estado a discricionariedade de proibir a ocorrência de uma reunião que obedeça a todas as exigências constitucionais. Com essa vedação, buscou-se evitar retaliações ou cerceamentos pela exposição de pensamentos que ofereçam ameaça à manutenção do sistema de poder vigente.

Nos países ditatoriais ou com falhas democráticas, é comum a restrição às liberdades de cunho político, como o direito de reunião, de manifestação, de associação, com

\footnotetext{
${ }^{11}$ Não se refere aqui aos pátios e centros de convivências peculiares às universidades federais, uma vez que, estes possuem, em regra, acesso aberto ao público em geral.

${ }^{12}$ Por tratar-se de um artigo científico específico sobre o direito de reunião, abstêm-se de analisar as "ocupações" sob enfoque de outro direito fundamental (manifestação, greve, etc) e seu possível conflito com outros bens jurídicos tutelados pela constituição (educação, liberdade de ir e vir, segurança, etc) - limitando-se à uma análise jurídica sob o prisma exclusivo do direito de reunião.
} 
o escopo de evitar a propagação de ideologias contrárias às da classe política dominante. Sendo assim, por ser um direito fundamental intimamente ligado ao processo democrático, na maioria das vezes, a realização de reuniões políticas expõem ideias dissonantes daquelas representadas pelos governantes no Poder.

A ausência de regulamentação sobre o tema produz incertezas jurídicas e deixa dúvidas sobre quem seria essa autoridade competente a ser comunicada sobre a reunião: polícia? Órgão de trânsito? município? estado?

À primeira impressão, pode-se imaginar que a não obediência dessa exigência comunicação prévia à autoridade competente - acarrete a exclusão da reunião da área de proteção do direito em comento. Entretanto, o pré-requisito de prévia comunicação não tem o condão de obstruir reunião não comunicada, desde que transcorra na normalidade e não afete gravemente a segurança pública, ordem social ou outro bem jurídico constitucionalmente relevante ${ }^{13}$.

Decerto, o melhor entendimento é que essa condicionante não atinge a área de proteção do direito fundamental à liberdade de reunião, apenas indica requisitos para o seu exercício e orienta o legislador ordinário ao regulamentá-lo.

4.2.5. "desde que não frustrem outra reunião anteriormente convocada para o mesmo local"

Ao prever a impossibilidade da realização de uma reunião que frustre outra anteriormente convocada, o constituinte busca solucionar o conflito entre a colisão de direitos idênticos, priorizando a antecedência do aviso de seu exercício.

Observa-se que o verbo utilizado (frustrar) possui um condão de inutilizar, privar a ocorrência da reunião. Nesse caso, a lesão advinda dessa nova reunião é de grau elevado e afeta o próprio exercício do direito de reunião pelas outras pessoas. Desta forma, o mero atrapalhar não pode ser considerado como obstrutivo à sua realização.

Por exemplo, havendo uma reunião em determinado local, a aglomeração de algumas pessoas em local próximo com o intuito de chamar a atenção, muitas vezes pode não significar efetivamente uma obstrução.

\footnotetext{
${ }^{13}$ Bem como, não frustre outra reunião anteriormente convocada para o mesmo local, conforme será analisado no item seguinte.
} 


\section{Dos limites do legislador na regulamentação do direito fundamental à liberdade de reunião}

Diante do vínculo estreito entre a participação política do povo e a liberdade de reunião, este direito só deverá ser cerceado em casos excepcionais. De fato, caso a ordem jurídica de um Estado esteja pautada em ideais como democracia e liberdade, a intervenção estatal sobre o direito de reunião deverá estar restrita às situações fora da área de proteção ou conflitantes com outros direitos fundamentais ou bens jurídicos constitucionais.

Contudo, ao regulamentar o direito fundamental à liberdade de reunião, o legislador infraconstitucional deve obedecer não apenas os ditames impostos pelo art. $5^{\circ}$, XVI da CF, mas a todo o texto constitucional, considerando eventuais conflitos com os demais direitos fundamentais e também com outros bens jurídicos tutelados pela Constituição.

De pronto, cumpre estabelecer que o referido inciso é uma norma passível de aplicação independente da existência de lei infraconstitucional - o que não implica a vedação de promulgação de lei que o regulamente. Por já ser autoaplicável, o Poder Legislativo se mantém inerte sem criar uma legislação abordando o tema, dando azo a controvérsias na construção dogmática e na aplicação do direito fundamental à liberdade de reunião.

Embora desnecessária juridicamente, uma lei que tenha por objeto os limites ao exercício do direito de reunião e regulamente os atos estatais em caso de conflitos com outros direitos também protegidos pela Constituição seria conveniente para contornar os abusos ocorridos tanto no exercício desse direito, como na atuação estatal em reprimir aquelas reuniões fora da área de proteção do art. $5^{\circ}$, XVI da CF.

Em outras palavras, caso o legislador infraconstitucional se preocupasse em aprovar uma normatização sobre o assunto, proporcionaria uma maior segurança jurídica para o Estado, para a sociedade e para os cidadãos que desejem exercer o seu direito subjetivo de reunir-se.

Contudo, o legislador jamais poderia restringir livremente o direito fundamental à liberdade de reunião, devendo apenas tratar de divergências interpretativas das expressões utilizadas no art. $5^{\circ}$, XVI da CF ou permitir uma intervenção estatal quando a reunião colidir com outros direitos fundamentais ou outros bens jurídicos de importância constitucional.

É sabido que o direito à reunião deve ser pacífico, desta forma, questiona-se as reuniões realizadas por grupos pré-dispostos a causar a desordem pública através de danos ao patrimônio (público ou privado) ou a integridade física de outros. As manifestações políticas 
ocorridas no Brasil em 2013 fomentaram a formação de um grupo autointitulado "blackblocks" e a sua base ideológica é lutar contra certos ideais através da desordem e de danos patrimoniais. Nesses casos, é evidente que, desde o início, padecem do vício da nãopacificidade, entretanto, surgem algumas indagações: pode ser proibida a convocação para essas reuniões? E a sua formação? Ou deve-se esperar a primeira conduta não pacífica para determinar a sua repressão? ${ }^{14}$

A abrangência da expressão "sem armas" também é alvo de questionamentos: deve ser interpretada restritivamente? As armas brancas estão incluídas por essa vedação? Apenas a arma de fogo? Quando o porte de arma realmente atinge a legitimidade da reunião?

Uma vez respondidos os questionamentos apresentados pelo legislador infraconstitucional, haveria uma maior segurança para todos os envolvidos nessa celeuma e os limites constitucionais estariam obedecidos, uma vez que a pacificidade e a ausência de armas são exigências intrínsecas ao art. $5^{\circ}$, XVI da CF.

Outro aspecto do direito de reunião carecedor de regulamentação é o prévio aviso à autoridade competente, a Constituição não deixa claro qual órgão ou agente público detém a atribuição de ser comunicado acerca da ocorrência de manifestações em locais públicos, o que leva a tentativas de cerceamento desse direito pela ausência de comunicação ou a realização de reuniões sem o conhecimento do Poder Público, o que pode dar ensejo a badernas indesejáveis, típicas em aglomerações de pessoas.

$\mathrm{O}$ legislador não poderia ir de encontro à literalidade do dispositivo constitucional. Isto é, seria uma patente violação à Constituição, exigir uma autorização do Estado para o exercício do direito fundamental à liberdade de reunião.

Diante disso, não cabe ao legislador, com a escusa de regulamentar o exercício do direito fundamental à liberdade de reunião, impor um requisito claramente afastado pelo constituinte originário.

O exercício do direito de reunião em diversas situações entra em conflito com os demais direitos fundamentais - a exemplo da liberdade de ir e vir, da autonomia privada, do direito à propriedade - ou com outros bens jurídicos também salvaguardados pelo texto constitucional - por exemplo, a paz social, ordem pública, segurança nacional - e, em alguns

\footnotetext{
${ }^{14}$ Não se procura analisar a formação dos autointitulados Blackblocks sobre a perspectiva de outro direito constitucional, limita-se à sua análise frente ao direito de reunião. Contudo, é próprio da ideologia desse grupo não submeter-se a legalidade ou à constituição. Ao contrário, a desordem e a ofensa ao sistema posto é um dos meios encontrados por eles para lutarem pelos seus direitos.
} 
momentos, dificulta ao Estado a garantia de determinados direitos sociais - como educação, saúde e transporte.

Diante disso, caberia ao legislador infraconstitucional tentar solucionar antecipadamente os problemas advindos desse choque de bens jurídicos relevantes, garantindo, assim, maior segurança jurídica e diminuindo as divergências jurídicas decorrentes da interpretação do texto constitucional.

\section{Conclusão}

O direito à liberdade, princípio basilar do Estado Democrático de Direito, encontra respaldo no art. $5^{\circ}$ da Constituição da República Federativa do Brasil. O ordenamento pátrio dispensou atenção ao direito genérico à liberdade, bem como a diversas liberdades específicas, entre essas, o direito à liberdade de reunião.

O direito de reunir-se livremente traduz a essência democrática desse Estado de Direito e é meio idôneo à população pressionar seus representantes a agirem respeitando a vontade popular. Contudo, assim como acontece com as demais espécies de direitos, os direitos fundamentais também não são absolutos, logo, o direito de reunião não é ilimitado. $\mathrm{O}$ próprio constituinte já recortou a área de proteção e condicionou seu exercício a determinados requisitos descritos no mesmo dispositivo que o assegura

Assim, a Constituição brasileira simultaneamente assegura o direito à liberdade de reunião, delimita a sua área de proteção e impõe condicionantes ao seu exercício. Entretanto, isso não veda totalmente a atuação do legislador infraconstitucional em regulamentar o tema, apenas deixa contornos claros a serem obedecidos, sob o risco de inconstitucionalidade.

Decerto, os requisitos previstos constitucionalmente para o exercício do direito de reunião, não são suficientes para solucionar eventual colisão com outros direitos fundamentais ou demais bens jurídicos de importância constitucional. Ao contrário, a ausência de norma dificulta muitas vezes a legítima intervenção estatal ou dá azo a intervenções inconstitucionais no exercício correto do direito de reunião.

Todavia, a discricionariedade do legislador ordinário não é plena. A sua atuação deverá ser guiada pelos limites constitucionais dispostos no art. $5^{\circ}$, XVI da CF e por possíveis choques com os demais direitos fundamentais (por exemplo, autonomia privada, liberdade de expressão, liberdade de ir e vir, saúde) ou outros bens jurídicos relevantes constitucionalmente (por exemplo, paz social, segurança e ordem pública). 
Diante disso, caberia ao legislador infraconstitucional tentar solucionar antecipadamente os problemas advindos desse conflito de bens jurídicos relevantes - que permitem a eventual limitação ao exercício do direito de reunião - garantindo, assim, maior segurança jurídica e diminuindo as divergências decorrentes da interpretação conferida ao texto constitucional.

\section{Bibliografia}

ALEXY, Robert. Teoria dos Direitos Fundamentais. Tradução: Virgílio Afonso da Silva. São Paulo: Malheiros, 2008.

BONAVIDES, Paulo. Curso de Direito Constitucional. 15 a edição. São Paulo: Malheiros, 2004.

BRITTO, Carlos Ayres. Teoria da Constituição. Rio de Janeiro: Forense, 2006.

CANOTILHO, JJ Gomes. Direito Constitucional e Teoria da Constituição. $7^{\text {a }}$ edição. Coimbra: Almedina, 2000. 539.

, J. J. Gomes. Direito Constitucional. $6^{\text {a }}$ Edição. Coimbra: Livraria Almedina, 1993, p.

, J.J. Gomes. MOREIRA, Vital. Constituição da República Portuguesa Anotada: artigos 108 a 296. Vol. I. 4 $4^{\text {a }}$ Edicao. Coimbra: Coimbra Editora, 2007.

DIMOULIS, Dimitri; MARTINS, Leonardo. Teoria Geral dos Direitos Fundamentais. $5^{\text {a }}$ ed. São Paulo: Atlas, 2014, p. 172.

FUX, Luiz. O direito de reunião na Constituição Federal de 1988. In: BRASIL. Supremo Tribunal Federal (STF). A Constituição de 1988 na visão dos Ministros do Supremo Tribunal Federal. Edição comemorativa. Brasília: Secretaria de documentação, 2013. p. 169-192. Disponível em: < http://bdjur.stj.jus.br/dspace/handle/2011/71069>. Acesso em: 21.maio. 2017.

HESSE, Konrad. A Força Normativa da Constituição. Tradução: Gilmar Ferreira Mendes. Porto Alegre: Sergio Antonio Fabris Editor, 1991.

Konrad. Os Direitos Fundamentais na República Federal. In: Temas fundamentais do direito constitucional/ Konrad Hesse; textos selecionados e traduzidos por Carlos dos Santos Almeida, Gilmar Ferreira Mendes, Inocêncio Mártires Coelho. — São Paulo: Saraiva, 2009.

HOBBES, Thomas, 1588-1679. Leviatã. Tradução: João Paulo Monteiro, Maria Beatriz Nizza da Silva, Claudia Berliner. Revisão da tradução Eunice Ostrensky. São Paulo: Martins Fontes, 2003. 
LASSALLE, Ferdinand. A Essência da Constituição. $6^{\text {a }}$ edição. Rio de Janeiro: Lumen Juris. p. 33

MARTINS, Leonardo. Liberdade e Estado Constitucional: leitura jurídico dogmática de uma complexa relação a partir da teoria liberal dos direitos fundamentais. São Paulo: Atlas, 2012.

MENDES, Gilmar Ferreira; COELHO, Inocêncio Mártires; BRANCO, Paulo Gustavo Gonet. Hermenêutica Constitucional e Direitos Fundamentais. Brasília Jurídica: Brasília, 2000.

TAVARES, André Ramos. Curso de direito constitucional. 11. ed. rev. e atual. - São Paulo: Saraiva, 2013. 